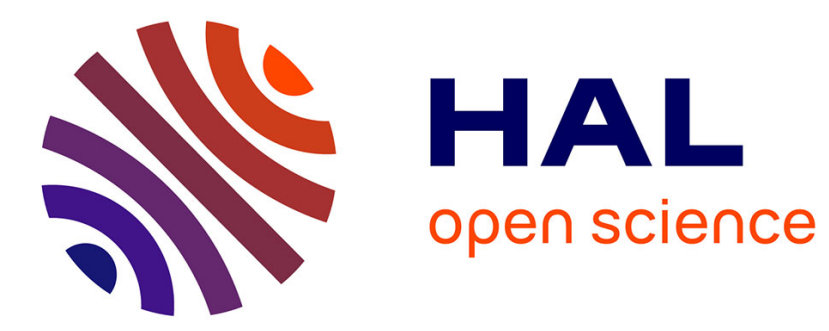

\title{
The peculiarities of image formation in photoacoustic microscope under piezoelectric detection
}

\author{
G. Bulakh, R. Burbelo, A. Gulyaev, P. Ilyin, I. Kucherov
}

\section{To cite this version:}

G. Bulakh, R. Burbelo, A. Gulyaev, P. Ilyin, I. Kucherov. The peculiarities of image formation in photoacoustic microscope under piezoelectric detection. Journal de Physique IV Proceedings, 1994, 04 (C7), pp.C7-23-C7-25. 10.1051/jp4:1994706 . jpa-00253147

\section{HAL Id: jpa-00253147 https://hal.science/jpa-00253147}

Submitted on 1 Jan 1994

HAL is a multi-disciplinary open access archive for the deposit and dissemination of scientific research documents, whether they are published or not. The documents may come from teaching and research institutions in France or abroad, or from public or private research centers.
L'archive ouverte pluridisciplinaire HAL, est destinée au dépôt et à la diffusion de documents scientifiques de niveau recherche, publiés ou non, émanant des établissements d'enseignement et de recherche français ou étrangers, des laboratoires publics ou privés. 


\title{
The peculiarities of image formation in photoacoustic microscope under piezoelectric detection
}

\author{
G.I. Bulakh, R.M. Burbelo, A.L. Gulyaev, P.P. Ilyin and I.Ya. Kucherov \\ Physics Faculty, Taras Shevchenko University, 252017 Kiev, Ukraine
}

\begin{abstract}
It has been shown that acoustic properties of the regions of the object located under the point of laser beam action and out of reach of the heat wave, play essential role in forming photoacoustic signal under piezoelectric registration. This fact can be used with the aim of visualization since the resulting photoacoustic topograms reflect the localization, shape and sizes of inhomogeneities sufficiently well.
\end{abstract}

\section{INTRODUCTION}

Photoacoustic microscopy (PAM) is used more and more widely for investigation of surface and subsurface regions in opaque objects [1-4]. In PAM preference is often given to piezoelectric detection of thermoelastic vibration. The analysis of topograms received by PAM method with piezoelectric registration normally suggests that if the acoustic wavelenght at the frequency of light modulation is much greater than the wavelenght of heat wave, the information about the object is obtained from the region of interaction of the heat wave with the subsurface region of the sample, as in the case of gasomicrophone registration [3].

However, this suggestion is sometimes not correct. For example, it has been shown in [5] that the quantity of photoacoustic (PA) signal depends upon the place of laser beam action even in case of homogeneity of the object under investigation (positional sensitivity of piezodetector). The question about possible influence on PA signal of characteristics of the sample volume, placed between the region of thermoelastic stress formation and piezodetector, has not been studied before

To clarify this question PAM investigations under piezoelectric registration were carried out on model samples with specially-created inhomogeneities -"defects" of structure in conditions when the heat wave did not reach this defects.

\section{TECHNIQUE AND SAMPLES}

The samples that have been studied were prepared of different materials and had defects of different forms. In aluminum plates cavities of cylindrical form were produced on the depth of $0,05-0,15 \mathrm{~mm}$ from the working (irradiated with light) surface. In the monocrystal silicon wafer (thickness $h=0,36 \mathrm{~mm}$ ) a technological mark (scratch) with the depth of about $0,1 \mathrm{~mm}$ and width of about $0,6 \mathrm{~mm}$. was put on non-

working surface. Also the bimorphous piezoceramic disks with defects of connecting joint were investigated. The bimorphs were produced from plates with $\mathrm{h}=0,27 \mathrm{~mm}$. The faces of this plates were 
metallized by silver and their connection was made by diffusion-welding. To create inhomogeneity of the connecting joint a cross-like indentation with the depth of several $\mu \mathrm{m}$ was made by chemical etching before metallization.

The investigations were carried out on PA microscope with the piezoelectric registration described in [4]. Piezodetector had diameter $30 \mathrm{~mm}$. Diameter of laser beam on the surface of sample was no more than $0,01 \mathrm{~mm}$. The frequency of modulation of light beam was $76 \mathrm{kHz}$ and it was chosen in a such way, that the heat diffusion lenght was less than the depth of defect location, i.e. the heat wave did not reach the defect. The heat wave lenth on given frequency was no more than $0,02 \mathrm{~mm}$ in all cases.

\section{RESULTS}

First it should be noted that there were not any peculiarities of the registrated signals in homogeneous samples, except the positional sensitivity of piezodetector. Results of the investigations of PA effect under scanning with laser beam on the surface of aluminum plate are presented on Fig.1. In the lower part of Fig. 1 the section of the sample along the line of moving laser beam is shown.

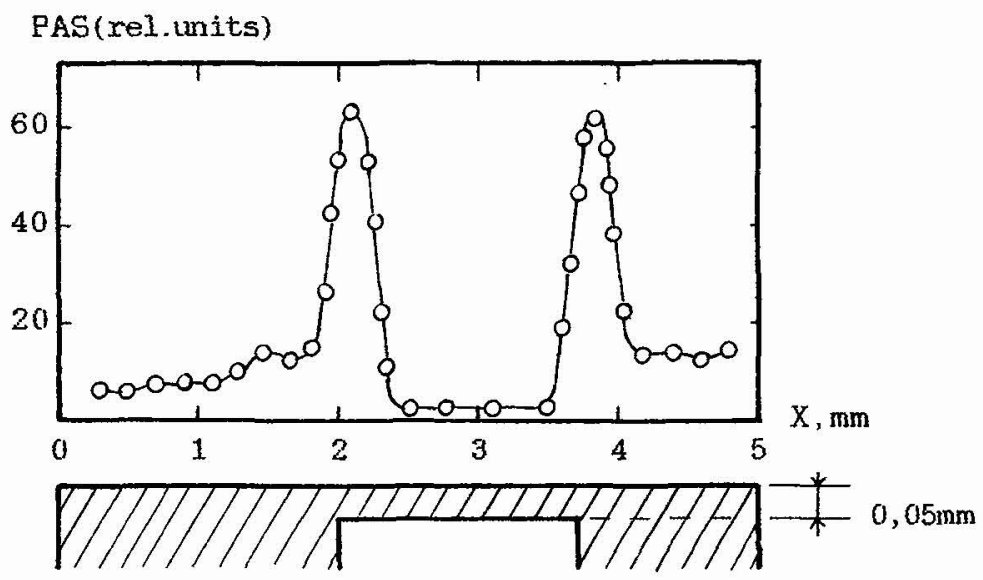

Fig.1

As it is seen from above results, PA signal amplitude in the region of defect is diminishing under piezoelectric registration, although the heat wave does not reach the defect. The heat diffusion lengh in aluminum at this frequency is $0,017 \mathrm{~mm}$ and it is smaller than the distance between the working surface and defect $(0,05 \mathrm{~mm})$. This testifies to the fact, that not only the region of heat wave action, but also the rest part of the object is taking part in forming PA signal under piezoelectric registration.

With the aim of further investigation of this question PAM topograms were taken for silicon plates and bimorphous ceramic disks. The PA topogram of the region with technological mark in silicon wafer is given on Fig.2.

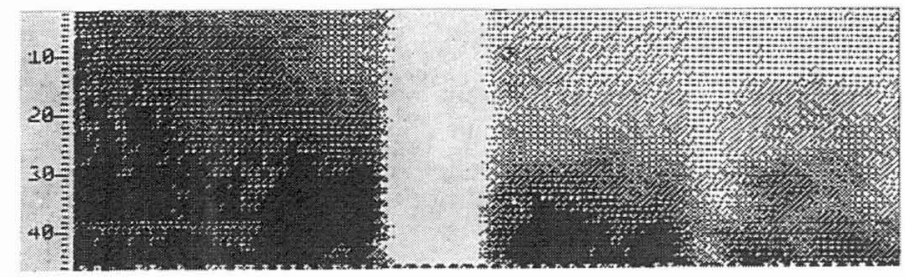

Fig.2. 
At this frequency the heat diffusion lenght in silicon is $0,015 \mathrm{~mm}$, the distance to the defect is $0,36 \mathrm{~mm}$. It should be noted that the width of bright strip on the topogram coincides with the width of technological mark. In the region of mark the amplitude of signal decreases as in the previous case.

Fig. 3 shows PA topogram of the region of bimorphous system containing cross-like defect of connecting joint (width of stripes - 3mm). One can see that if the defect is placed inside the object under study, and the heat wave does not reach it, the topogram reproduces the shape and localization of the defect sufficiently well.

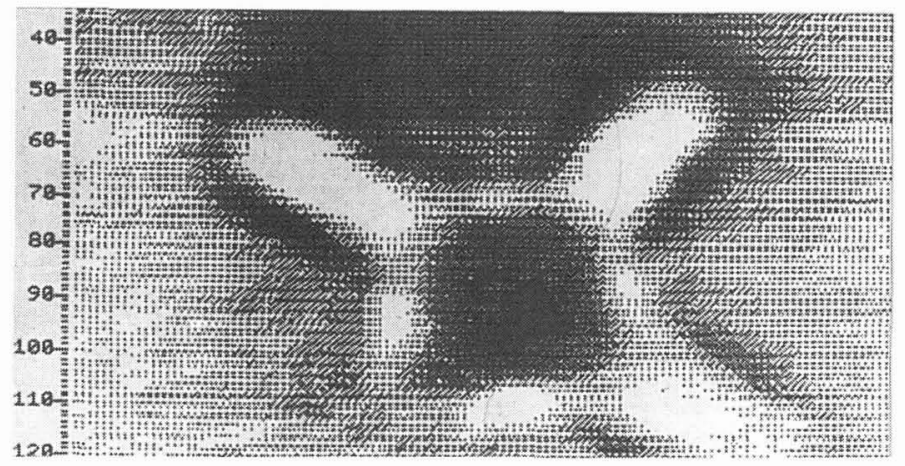

Fig.3.

\section{CONCLUSIONS}

Thus, the investigations have shown that in the object under investigation acoustic properties of the regions which are located under the place of laser beam action and out of reach of heat wave, play essential role in forming of PA signal under piezoelectric registration. In some cases, as, for example, in the experiments described in this paper, this circumstance can play the leading role, despite of the fact that image formation is taking place on the acoustic wavelenght much greater than both the defect size and the sample size. This fact can be used with the aim of visualization since the photoacoustic topograms obtained reflect localization, shape and sizes of inhomogeneities sufficiently well.

\section{REFERENCES:}

[1] G.Busse, "Imaging with Optically Generated Thermal Wawes", Physical Acoustics, ed. by W.P.Mason and R.N.Thurston, XVIII (Academic Press, New York, 1988)pp.403-478.

[2] Mandelis A., Ed., Photoacoustic and thermal wave phenomena in semiconductors (Elsevier, Amsterdam, 1987).

[3] Rosencwaig A., Photoacoustic and Photoacoustics Microscopy (John Wiley and Sons, New-York etc., 1980) p.310.

[4] Bulakh G.I., Burbelo R.M., Gulyaev A.L., Kucherov I.Ya., "Photoacoustic Microscopy of semiconductor structures using piezoelectric detection", Polycristalline semiconductors II,(Springer Proceeding in Physics, Springer-Verlag, 54, 1991)pp.109-114.

[5] Bulakh G.I., Burbelo R.M., Gulyaev A.L., Zhabitenko N.K., Kucherov I.Ya., J.Tekhnicheskoi fiziki, 10 (1992) 86-93, (in Russian). 